therefore, we were not able to stratify patients according to the lot number. A relationship between the total volume of polygeline used in the operating room and the development of adverse reactions was found, suggesting a dose-dependent effect. However, our study was limited by the relatively small number of cases included (as evidenced by the wide $\mathrm{CI}_{95}$ for many of the $\mathrm{OR})$, resulting in a low power of the multiple logistic regression analysis to identity important variables as independent predictors.

An alternative explanation for the outbreak was that those patients requiring higher volumes of plasma expander were more likely to become hypotensive because of another unknown underlying process, which resulted in the requirement for more plasma expander in the first place. However, the etiologic role of the polygeline was supported by the biological dose response trend and by control of the outbreak once the use of polygeline was discontinued. Furthermore, the manufacturer was notified of other cases of isolated mild adverse events (fever and hypotension), possibly related to polygeline, in several hospitals from Spain and other European countries (Italy, France, and The Netherlands).

The contamination of blood, blood products, intravenous fluids, or drugs is an uncommon source of epidemics or pseudoepidemics in hospitals. In such cases, the identification of a risk factor or common source is not an easy task, and clinicians and epidemiologists always should be aware of new potential sources of clusters of adverse events.

\section{R E F E R E N C E S}

1. Freeman MK. Fatal reaction to haemaccel. Anesthesis 1979;34:341-343.

2. Barrat S, Purcell GJ. Refractory bronchospasm following haemaccel infusion and bupivacaine epideural anesthesia. Anaesth Intensive Care 1988;16:208-211.

3. Jurado AS, Piheiro TJ, Madeira VM. Physical studies on membrane lipids of Bacillus stearothermophilus temperature and calcium effects. Arch BiochemBiophys1991;289:167-179.

4. Breitwieser A, GruberK, Sleytr UB. Evidence for an S-layer protein pool in the peptidoglycan of Bacillus stearothermophilus.J Bacteriol 1992;174:80088015.

5. Forrest TM, Wilson GE, Pan Y, Schaefer J. Characterization of crosslinking of cell walls of Bacillus subtilis by a combination of magic-angle spinning NMR and gas chromatography-mass spectrometry of both intect and hydrolyzed $13 \mathrm{C}$ - and $15 \mathrm{~N}$-labeled cell-wall peptidoglycan. $J$ Biol Chem 1991;266:24485-24491.

6. Hemila H. Sequence of a PAL-related lipoprotein from Bacillus subtilis. FEMS Microbiol Lett1991;66:37-41.

7. Noble RC, Reeves SA. Bacillus species pseudosepsis caused by contaminated commercial blood culture media. JAMA 1974;230:1002-1004.

8. Berger SA. Pseudobacteremia due to contaminated alcohol swabs. J Clin Microbiol1983;18:974-975.

9. Gurevich I, Tafuro P, Krystofiak SP, Kalter RD, Cunha BA. Three clusters of Bacillus pseudobacteremia related to a radiometric blood culture analyzer. Infect Control 1984;5:71-74.

10. Centers for Disease Control. Bacterial contamination of platelet poolsOhio, 1991. MMWR1992;41:36-37.

11. Goldstein B, Abrutyn E. Pseudo-outbreak of Bacillus species related to fiberoptic bronchoscopy. J. Hosp Infect 1985;6:194-200.

12. Richardson AJ, Rothburn MN, Roberts C. Pseudo-outbreak of Bacillus species related to fiberoptic bronchoscopy. J Hosp Infect 1986;7:208-210.

13. LeHau LA, Benjamin D, Cantrell HE Potts DW, Boggs JM. Bacillus species pseudomeningitis. Infect Control Hosp Epidemiol 1989;9:394-397.

14. Bryce EA, Smith JA, Tweeddale M, Andruschak BJ, Maxwell MR Dissemination of Bacillus cereus in an intensive care unit. Infect Control Hosp Epidemiol 1993;14:459462.

\title{
Community Outbreak of Legionnaires' Disease from Hospital Cooling Tower
}

\section{by Gina Pugliese, RN, MS Medical News Editor}

From July to September 1994, 29 cases of Legionnaires' Disease (LD) were reported to the Delaware health department. None of the cases were nosocomial despite the fact that they were linked to the hospital. A casecontrol study was conducted after control procedures were instituted. Microbiological assays were performed on waters from the hospital cooling towers and from eight nearby cooling towers. Hospital staff and adjacent census tract residents had the highest incidence of LD pneumonia. Legionella pneumophila serogroup 1 (LP1) was isolated from four case patients and both hospital cooling towers, but from none of the other cooling towers. The isolates were subtyped by monoclonal antibody analysis and arbitrarily primed polymerase chain reaction. The four cooling tower isolates had the same patterns as did isolates from two cases who lived or worked within a mile of the tower. The other two cases had a different subtype and had not been within a mile of the tower. Twenty-one cases had worked at or had visited the hospital. By point of closest contact, the odds ratio (OR) for illness decreased by $20 \%$ for each 0.1 mile from the hospital.
Each hospital visit increased the OR by $80 \%$, whereas visits to more distant sites only increased the OR by $29 \%$ to $66 \%$.

The investigators concluded that epidemiologic and typing results identified the hospital cooling towers as the source of the community outbreak of LD, and that increased proximity and frequency of exposure to the hospital increased the risk.

FROM: Brown CM, Nuorti P, Fields B, et al. Community outbreak of Legionnaires' Disease. Abstracts of the 44th Annual Epidemic Intelligence Service Conference. March 27-31, 1995; Atlanta, Georgia. 